\title{
Fundamental motor skills of Czech children at the end of the preschool period
}

\author{
Jakub Kokštejn ${ }^{1}$, Martin Musálek ${ }^{1}$, Petr Štastný1,*, and Artur Golas ${ }^{2}$ \\ ${ }^{I}$ Faculty of Physical Education and Sport, Charles University, Prague, Czech Republic; and ${ }^{2}$ The Jerzy Kukuczka Academy \\ of Physical Education in Katowice, Katowice, Poland
}

Copyright: (C) 2017 J. Kokštejn et al. This is an open access article licensed under the Creative Commons Attribution License (http://creativecommons.org/licenses/by/4.0/).

\begin{abstract}
Background: Achievement of a sufficient fundamental motor skills (FMS) level by the end of the preschool period is an important premise for the later participation of children in many sports activities. However, only a few studies have focused on the assessment of motor proficiency before entrance to elementary school in the population of preschool children in the Czech Republic. Objective: The aim of this study was to assess the FMS of Czech boys and girls at the end of the preschool period. Methods: The Movement Assessment Battery for Children-second version (MABC-2) was used to assess the motor performance of the children in different domains, i.e., manual dexterity, aiming and catching, and balance. The research sample consisted of 121 children (age $6.5 \pm 0.3$ years, 61 boys and 60 girls). Results: According to the total test score performance on MABC-2, we found $2.5 \%$ of children with severe motor difficulties indicating the possible presence of Developmental Coordination Disorder and $10.7 \%$ of children with a risk of motor difficulties. In total, $64 \%$ of boys and $81.6 \%$ of girls had an MABC-2 score in the $50^{\text {th }}$ percentile or lower. With respect to gender differences, boys outperformed girls in aiming and catching skills $(p<.001 ; d=1.10)$. Moreover, the girls' score in the $25^{\text {th }}$ percentile indicated a low level of aiming and catching skills. Despite significantly better results for boys in one manual dexterity test item, and for girls in one manual dexterity and balance test item, there were no significant gender differences in overall manual dexterity and balance subtests. Conclusion: With the preschool years being a key developmental stage for the acquisition and development of FMS, the findings of low level of FMS in most of children and gender differences in aiming and catching skills highlight the need for improvements in motor competency. An effort should be made, especially for preschool girls, to stimulate the improvement of aiming and catching skills.
\end{abstract}

Keywords: motor development, preschool age, gender differences, MABC-2

\section{Introduction}

Motor competence, in terms of acquisition of fundamental motor skills (FMS) (which subsequently supports healthy growth and neuromuscular development), is one of the main goals of preschool education in the Czech Republic (Research Pedagogical Institute in Prague, 2004). FMS are considered to be fundamental building blocks of more complex and specialized motor skills, which are required for the successful participation of children in many daily, social, sport, and life activities (Gallahue, Ozmun, \& Goodway, 2011; Sugden \& Wade, 2013; Valtr, Psotta, \& Abdollahipour, 2016). Moreover, FMS, together with the

\footnotetext{
* Address for correspondence: Petr Štastný, Department of Sport Games, Faculty of Physical Education and Sport, Charles University, José Martího 269/31, 16252 Prague 6, Czech Republic. E-mail: stastny@ftvs.cuni.cz
}

self-perception of physical competence and health related fitness, play a key role in helping to predict levels of physical activity and obesity in the population of children (Chagas \& Batista 2017; Stodden et al., 2008). The results of several studies have shown that an adequate level of FMS significantly correlates with higher levels of physical activity (Barnett, van Beurden, Morgan, Brooks, \& Beard, 2009; Okely, Booth, $\&$ Patterson, 2001). Most often, FMS are divided into "locomotor" (walking, running, jumping, hopping, galloping, etc.), "manipulation" (catching, throwing, kicking), and "balance" (changes of positions and movements during standing and while moving, standing on one leg, walking on tip-toes, etc.) skills (Stodden et al., 2008).

A substantial body of literature focuses on the development of FMS during early childhood, in children 3-6-years-old (Gallahue et al., 2011; Haywood 
\& Getchell, 2014; Stodden et al., 2008). However, most of these studies are only taken into consideration when dysfunction or inefficient motor behavior appears (Davies, 2003). Thus, current research in the area of FMS development focuses, mainly, on motor impairment and motor deficits (Cools, De Martelaer, Samaey, \& Andries, 2009). Studies which focus on the assessment of FMS within a population of typically developing preschool children are rather scarce (Cools et al., 2009; Vandaele, Cools, de Decker, \& de Martelaer, 2011). Hardy, King, Farrell, Macniven, and Howlett (2009) suggest that children should achieve an adequate level of FMS by the end of the preschool period, around the age of six. In general, it is assumed that FMS are established between four and six years of age, and at the age of six and a half, a child should have reached mature-stage FMS (Gallahue et al., 2011).

Several studies focusing on assessment of FMS have pointed out poor or insufficient levels of FMS in relation to the healthy development of preschool children (Hardy et al., 2009; LeGear et al., 2012; Vandaele et al., 2011). A generally low level of FMS was found by Hardy et al. (2009), in Australia, in 330 preschool children aged four years. Based on these results, the authors suggest that developmentally appropriate interventions should be implemented in preschool settings to promote FMS, with targeted activities for boys and girls. A low level of FMS (16-24 $4^{\text {th }}$ percentile range) was also found in a study by LeGear et al. (2012), which primarily explored the relationship between the level of motor skills proficiency and the self-perception of competence in 260 Canadian preschoolers. Though the motor skills level was quite low, the children held generally positive perceptions of their physical competence, which provided a window of opportunity for fostering skillfulness (LeGear et al., 2012).

Gender differences in FMS proficiency have been found during early childhood, and can be attributed to a complex interaction between environmental, sociocultural, and biological factors (Malina, 2004; Thomas \& French, 1985). Temple, Crane, Brown, Williams, and Bell (2016) suggested that young boys and girls may already have different physical activity preferences, which perhaps lead to differences in motor skills proficiency. Although there are often no differences, by gender, in terms of total FMS test scores, boys and girls often have different levels of specific subtest scores in locomotor, object control and balance skills (see Foulkes et al., 2015; Hardy et al., 2009; Kokštejn, Musálek, \& Tufano, 2017). Generally, better object control skills have been found in boys (Foulkes et al., 2015; Hardy et al., 2009; Kokštejn et al., 2017; Livesey, Coleman, \& Piek, 2007; Spessatto, Gabbard, Valentini, \& Rudisill, 2013). Conversely, girls' locomotor proficiency has more often been reported as higher than boys (Barnett, Morgan, van Beurden, \& Beard, 2008; Hardy et al., 2009; van Beurden, Zask, Barnett, $\&$ Dietrich, 2002). Most studies focused on balance or fine motor skills have found better results in girls (Flatters, Hill, Williams, Barber, \& Mon-Williams, 2014; Livesey et al., 2007; Sigmundsson \& Rostoft, 2003; Venetsanou \& Kambas, 2011; Vlachos, Papadimitrou, $\&$ Bonoti, 2014), or have not revealed any significant gender differences (Shala, 2009; Singh et al., 2015; Van Waelvelde, Peersman, Lenoir, Smits Engelsman, \& Henderson, 2008).

To be physically active and engage in sport-specific skills, the development of different performance areas such as stability, locomotion, object control and fine motor skills is necessary (Vandaele et al., 2011). Additionally, as early as the preschool period, gender differences in FMS may be an important factor to consider when creating effective motor interventions for the development of FMS (Cliff, Okely, Smith, \& Mckeen, 2009). Research on motor development and FMS specifically in preschool children at six years of age has been limited in the Czech Republic. For this reason, the aim of the present study was to examine the level of FMS from areas of stability, fine, and gross motor skills in Czech children at the end of the preschool period (six years of age). Simultaneously, we examined whether motor performance involved in the MABC-2 test could be affected by gender.

\section{Methods}

\section{Participants}

The research sample consisted of 121 six-year-old preschool children (age $6.5 \pm 0.3$ years; 61 boys and 60 girls) from eight randomly selected kindergartens in Prague, Czech Republic. Only children with sensorimotor, physical, or cognitive disabilities known to the teachers were excluded from the study. The research, and the necessary informed consent forms, were approved by the Institutional Ethics committee of the Faculty of Physical Education and Sport at Charles University, Prague, in accordance with the ethical standards of the Helsinki Declaration of 1983. A signed informed consent form was received from parents of each child participating in this study.

\section{Instrument}

The test of the Movement Assessment Battery for Children-2 Age Band 1 (MABC-2 AB1 test; Henderson, Sugden, \& Barnett, 2007) was used for an assessment of FMS proficiency with norms for a population of Czech preschool children (Psotta, 2014). The MABC-2 test 
can be considered the most comprehensive diagnostic tool currently in use for the assessment of motor development, and for the identification of movement difficulties of varying severities (Henderson et al., 2007). The MABC-2 assesses motor performance using eight tasks subdivided into three domains: manual dexterity (MD), aiming and catching (AC), and balance (BAL). Detailed instructions for administering the tasks are given in the test manual (Psotta, 2014).

Following the Examiner's Manual (Henderson, et al., 2007; Psotta, 2014), the raw score of each test item was converted to an age-normed standard score. The overall FMS proficiency was expressed as a total test score (TTS) - calculated as the sum of the standard scores of all eight test items, and converted to standard score, and percentile equivalents. Proficiency in the different motor subtests (MD, AC, and BAL) was then calculated in the same way. According to the manual, TTS at or below the $5^{\text {th }}$ percentile identifies the presence of significant motor difficulties, and in many cases serves as an indicator of Developmental Coordination Disorder. A TTS between the $6^{\text {th }}$ and $16^{\text {th }}$ percentile, inclusive, is considered a risk for the presence of motor difficulties, with a TTS above the $16^{\text {th }}$ percentile showing typical motor coordination development (Henderson et al., 2007; Psotta, 2014).

\section{Procedure}

The MABC-2 was used in accordance with the directions specified in the test manual. A team of four trained research assistants (with Master's degrees in Physical Education and Sport, Adapted Physical Education, or Physiotherapy) tested children using the MABC-2 test $A B$ 1. Before official testing, and under the supervision of the primary author (an MABC-2 certified tester), all examiners completed the user's training program, which focused on understanding the theoretical background, and on the practical administration and scoring of the test. Each research assistant was responsible for two of the MABC-2 tasks, meaning that there were no inter-rater testing procedures. All testing occurred in a quiet kindergarten classroom during morning class time, and the children were tested in small groups (2-3 children per group). The order of all eight tests was randomized, as is allowed by the test manual, and the tests were performed on the same day. Children were familiarized with each test item through demonstration and trial attempts. Then, children completed official attempts according to the test manual, and the best score from each test was used for data analysis.

\section{Statistical analysis}

Percentile and standard scores were used to interpret FMS proficiency and gender differences in TTS, MD, $\mathrm{AC}$, and BAL and eight test tasks. To compare the data of the boys and girls groups, independent two-sample $t$-test was used. The significance level was set at $p<.05$. The effect size was tested with Cohen's coefficient $(d)$, using pooled $S D$ (Cohen, 1988). The value $d<0.50$ was interpreted as a small effect, $d=0.50-0.80$ as a moderate effect, and $d>0.80$ as a large effect (Cohen, 1988). Statistical analyses were conducted using the IBM SPSS Statistics (Version 22; IBM, Armonk, NY, USA).

\section{Results}

Table 1 shows the distribution for the total sample ( $N=121)$, based on the children's performance, and according to the norms offered by the MABC-2 test manual. At the end of the preschool period, the prevalence of significant motor difficulties was $2.5 \%(n=3)$. The prevalence of children at risk for presence of motor difficulties was $10.7 \%(n=13)$. A more detailed distribution of FMS proficiency is shown in Figure 1 for all preschool children and in Figure 2 for children by gender. Generally, we found FMS proficiency at or below the population mean in $81.6 \%$ of girls and $64 \%$ of boys (Figure 2). No children reached an FMS score $>95^{\text {th }}$ percentile, which points to a very high level of FMS proficiency.

No gender differences were found, except for the AC subtest, where boys outperformed girls $(t=5.92$, $p<.001, d=1.10$, Figure 3). Differences in the AC subtest were confirmed by the significantly better results for boys, in both the $\mathrm{AC} 1(t=4.58, p<.001, d=0.79$;

Table 1

Incidence of motor difficulties based on the total test score (TTS) according to the MABC-2 Age Band 1 test norms

\begin{tabular}{lcccc}
\hline & & $\begin{array}{c}\text { Significant motor difficulty, } \\
\text { TTS } \leq 5^{\text {th }} \text { percentile }\end{array}$ & $\begin{array}{c}\text { Risk of motor difficulty, } \\
\text { TTS }=6-16^{\text {th }} \text { percentile }\end{array}$ & $\begin{array}{c}\text { Without motor difficulty, } \\
\text { TTS }>16^{\text {th }} \text { percentile }\end{array}$ \\
\hline Total & 121 & $3(2.5 \%)$ & $13(10.7 \%)$ & $105(86.8 \%)$ \\
Boys & 61 & $1(1.7 \%)$ & $7(11.5 \%)$ & $53(86.8 \%)$ \\
Girls & 60 & $2(3.3 \%)$ & $6(10.0 \%)$ & $52(86.7 \%)$ \\
\hline
\end{tabular}




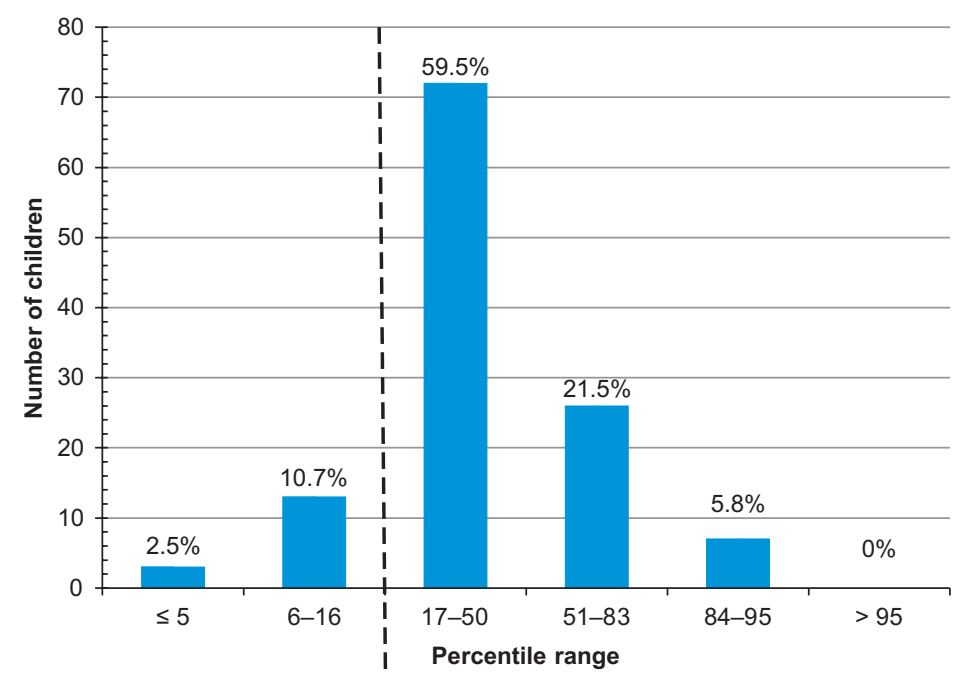

Figure 1. Total sample distribution according to MABC-2 test norms $\left(\leq 5^{\text {th }}\right.$ percentile $=$ significant motor difficulties, $6-16^{\text {th }}$ percentile $=$ risk of motor difficulties, $>16^{\text {th }}$ percentile $=$ no motor difficulties). The dashed line divides the children with and without any motor difficulties.

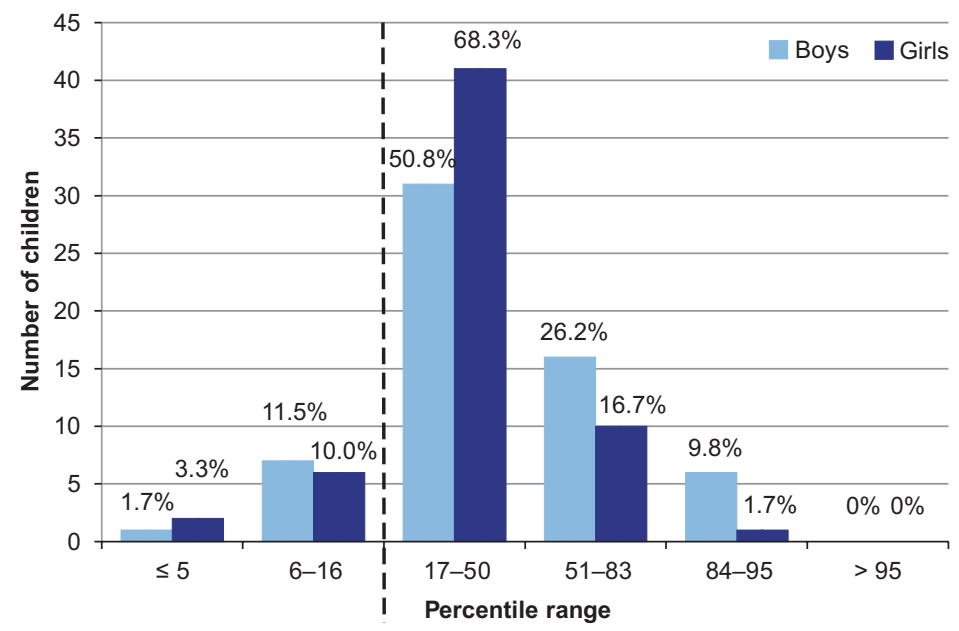

Figure 2. Distribution in relation to gender according to MABC- 2 test norms $\left(\leq 5^{\text {th }}\right.$ percentile $=$ significant motor difficulties, $6-16^{\text {th }}$ percentile $=$ risk of motor difficulties, $>16^{\text {th }}$ percentile $=$ no motor difficulties). The dashed line divides the children with and without any motor difficulties.

Figure 4) and AC2 test items $(t=3.16, p=.002$, $d=0.54)$. We found no gender differences in the MD and BAL subtests. However, girls outperformed boys in the MD2 $(t=2.90, p=.040, d=0.56)$ and BAL3 $(t=2.04, p=.004, d=0.60)$. On the contrary, boys were significantly better in the MD1 test item $(t=2.35$, $p=.020, d=0.42)$.

\section{Discussion}

The purpose of the present study was to examine the actual level of FMS in Czech children at the end of the preschool period. An additional aim of the study was to examine possible gender differences in FMS proficiency. Based on our results, only 2,5\% $(n=3)$ 


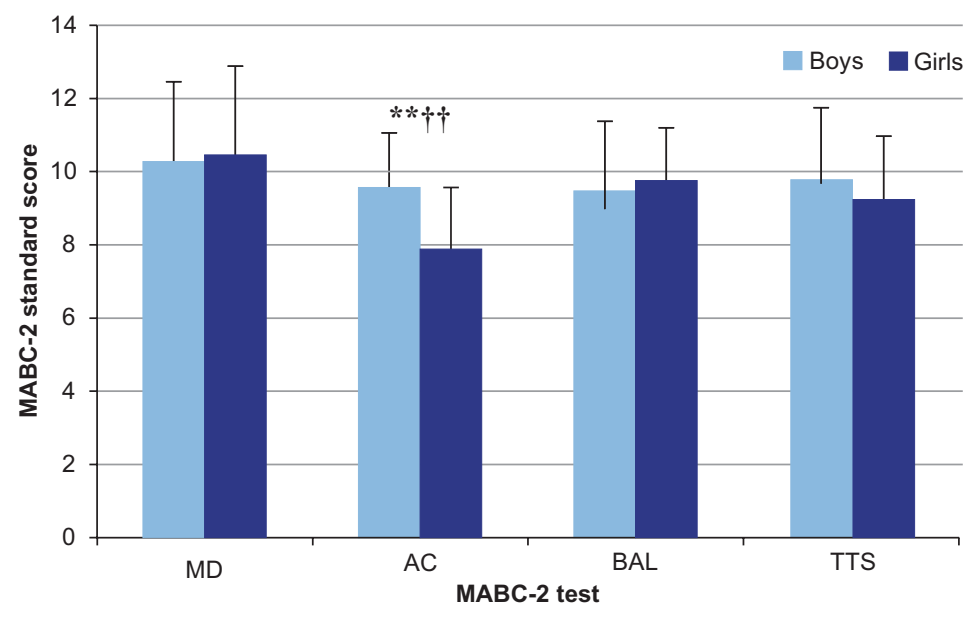

Figure 3. Comparison of the means of the three motor domains and the total test score of the MABC-2 between boys and girls. $\mathrm{MD}=$ manual dexterity; $\mathrm{AC}=$ aiming and catching $; \mathrm{BAL}=$ balance; TTS $=$ total test score. $\quad{ }^{* *} p<.01, \uparrow \dagger d>0.80$

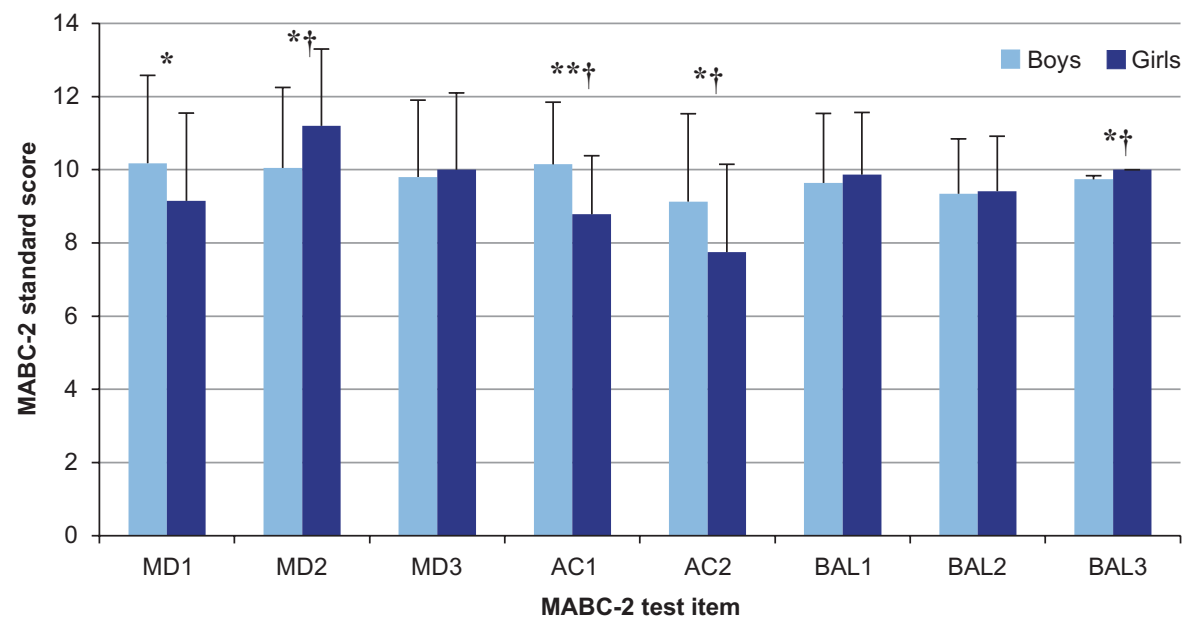

Figure 4. Comparison of the means of eight motor tasks of the MABC-2 between preschool boys and girls. $\mathrm{MD}=$ manual dexterity; $\mathrm{AC}=$ aiming and catching; BAL=balance. $\quad{ }^{*} p<.05,{ }^{* *} p<.01, \uparrow d=0.50-0.80$

of children showed significant (definite) motor difficulties, which are often associated with a probable presence of Developmental Coordination Disorder (DCD). The prevalence of DCD, of varying severity, in children aged 5-11 years is 5-6\% (American Psychiatric Association, 2013). However, in a study by Lingam, Hunt, Golding, Jongmans and Emond (2009) more than 7,000 children aged 7-8 years were tested, and a prevalence of only $1.8 \%$ of children with severe DCD was found. Therefore, our findings seem to be in accordance with the results of Lingam et al. (2009) where the authors used strict criteria for exclusion of children (test score on MABC- $2 \leq 5^{\text {th }}$ percentile) and did not include children at risk of motor difficulties (test score on MABC-2 $6-16^{\text {th }}$ percentile) as some other studies did. Despite the relatively small sample size in our study, the conclusion is that the prevalence of DCD among Czech children at the end of the preschool period is significantly lower in comparison to international studies reported by American Psychiatric Association (2013). According to the MABC-2 test manual, we suggested additional specialized examinations to parents whose children scored at or below the $5^{\text {th }}$ percentile on the MABC-2 test (clinical-psychological, pediatric, and neurological) which are necessary for the final designation of having DCD (Henderson et 
al., 2007). The prevalence, found in our study, of $10.5 \%$ of children at risk for DCD is similar to the results of Kourtessis et al. (2009) and Schoemaker, Lingam, Jongmans, van Heuvelen, and Emond (2013), who found values of $10.8 \%$ for Greek children, and $13.5 \%$ for English children, respectively. It is widely accepted that DCD shows stability over time, and without early identification and intervention the prognosis does not look promising (Kourtessis et al., 2009). Therefore, it is possible that children found to be "at risk" in our study have the potential for development of DCD in the future. These children should be monitored in the long term and tested repeatedly.

A more detailed distribution of children's FMS proficiency on the MABC-2 showed that $72.7 \%$ of children performed at or below the $50^{\text {th }}$ percentile, compared to norms for the population of Czech preschool children. In terms of gender differentiation, $81.6 \%$ of girls scored at or below the $50^{\text {th }}$ percentile, in comparison to $64 \%$ of boys. Generally, these results reflect recent findings about the low level of FMS proficiency in preschool children (Foulkes et al., 2015; Hardy et al., 2009; LeGear et al., 2012). The poor level of FMS proficiency found in our study becomes more important because some studies have found that higher FMS proficiency in childhood results in a higher level of physical activity during adolescence (Barnett et al., 2009; Barnett, van Beurden, Morgan, Brooks, \& Beard, 2010). Therefore, adequate motor intervention programs should be proposed and recommended for preschool children, to increase the level of FMS proficiency with respect to healthy development during the preschool stage. These programs should be especially designed for those children who scored at or below the $16^{\text {th }}$ percentile on the MABC-2, and whose FMS seem to indicate a risk for further health development.

According to the test manual, the mean value of both boys ( $48^{\text {th }}$ percentile) and girls $\left(42^{\text {th }}\right.$ percentile) points to optimal motor development. The total test score on the MABC-2 did not differ significantly between boys and girls. However, in the AC subtest, boys outperformed girls. Girls performed significantly lower in both "catching a beanbag (AC1)" and "throwing a beanbag onto mat (AC2)" test items. Our results are in accordance with previous studies which also found a significantly lower performance of objectcontrol skills in girls (Hardy et al., 2009; van Beurden et al., 2002; Van Waelvelde et al., 2008; Vandaele et al., 2011). Moreover, the overall score on the AC subtest for girls ( $25^{\text {th }}$ percentile) highlights poor object-control skills at the end of the preschool time. Gender differences in these skills during preschool years are attributed to cultural context, rather than different biological maturation (Malina, 2004; Thomas, 2000). It has been hypothesized that environmental and socio-cultural factors may partly explain why preschool boys generally outperform girls at object control skills, as girls spend more time in language, literacy, art, and fine motor activities, and boys in a number of different ball games and gross motor activities (Nelson, Thomas \& Nelson, 1991; Thomas \& French, 1985). For example, in a study by Blatchford, Baines, and Pellegrini (2003), 7-8-year-old boys spent significantly more time in playgrounds, especially playing ball games, than girls. According to this study, participation in a number of recreational and sport activities is conditioned by a sufficient level of object-control skills (e.g. aiming, throwing, kicking, and striking). The results of some studies found that higher proficiency in object-control skills was positively associated with a higher level of physical activities in adolescence (Barnett et al., 2009, 2010).

No gender differences were found for the manual dexterity subtest. However, for the individual MD test items, it was found that boys outperformed girls on the MD1 item, whereas girls outperformed boys on the MD2 item. Since better manual skills have been more often mentioned for girls (Flatters et al., 2014; Livesey et al., 2007; Sigmundsson \& Rostoft, 2003), it is surprising that better performance has not been confirmed for girls in test items MD1 and MD3. Generally, higher manual skills performance in girls has often been attributed to the early interest of girls in activities including fine motor skills (e.g. drawing, playing with dolls, sedentary games) (Blatchford et al., 2003). Our findings are in accordance with the results of Vandaele et al. (2011) who also did not find any significant differences between typically developing preschool boys and girls at the age of six. However, these authors did not support their results by any possible explanation. Kokštejn et al., (2017) found higher manual skills in 3- and 4-year-old children but not in 5- and 6-year olds. The authors suggest that the faster maturation of girls' brains, in comparison to boys, may be a possible cause of better fine motor skills in younger girls (see Hanlon, Thatcher \& Cline, 1999). Later, around the age of six, the rate of brain maturation becomes equal between boys and girls, and performance in overall manual skills is similar.

The results of boys and girls in the balance subtest $\left(46^{\text {th }}\right.$ and $47^{\text {th }}$ percentile) suggest adequate motor development. Although girls outperformed boys in all three test items (BAL1-3), significant gender differences occurred only in BAL3. Thus, our findings are in accordance with the results of previous studies, which also found no overall gender differences in the balance skills area (e.g. Singh et al., 2015; Van Waelvelde et al., 2008). It must be noted that some authors highlight that, with respect to gender differences, the findings 
on balance proficiency are conflicting (Kokštejn et al., 2017; Venetsanou \& Kambas, 2011).

As a limitation of our study, a relatively small sample size from only one Czech region could be considered. This fact does not allow us to generalize the results for a wider population of Czech preschool children. Another limitation of this study was a lack of information about the previous physical experience of the children (e.g. type of leisure time activities; level, and frequency, of participation in organized physical activities) which may affect the actual level of FMS. The MABC-2 test focuses only on quantitative aspects of motor skills which do not allow to define specific components of a skill an individual needs to practice. Therefore, better insight into the motor development of FMS could be obtained by using a combination of quantitative and qualitative techniques, together with an objective assessment of daily physical activity, designed longitudinally to encompass the entire preschool period.

\section{Conclusion}

Based on the results, we found $13.2 \%$ of children with severe to mild motor difficulties, which may be associated with the probable presence of DCD. Suitable interventional programs should be proposed, especially for these children, to improve FMS proficiency before entrance to elementary school. The low performance of girls in aiming and catching skills shows that girls need more improvement in object control skills during early childhood.

\section{Acknowledgments}

The study was supported by the Czech Science Foundation, project No. 14-29358P, and the Progres Q19 Social-Sciences Aspects of Human Movement Studies II program.

\section{Conflict of interest}

There were no conflicts of interest.

\section{References}

American Psychiatric Association. (2013). Diagnostic and statistical manual of mental disorders (5th ed.). Washington, DC: Author.
Barnett, L. M., Morgan, P. J., van Beurden, E., \& Beard, J. R. (2008). Perceived sports competence mediates the relationship between childhood motor skill proficiency and adolescent physical activity and fitness: a longitudinal assessment. International Journal of Behavioral Nutrition and Physical Activity, 5, 40.

Barnett, L. M., van Beurden, E., Morgan, P. J., Brooks, L. O., \& Beard, J. R. (2009). Childhood motor skill proficiency as a predictor of adolescent physical activity. Journal of Adolescent Health, 44, 252-259.

Barnett, L. M., van Beurden, E., Morgan, P. J., Brooks, L. O., \& Beard, J. R. (2010). Gender differences in motor skill proficiency from childhood to adolescence: A longitudinal study. Research Quarterly for Exercise and Sport, 81, 162-170.

Blatchford, P., Baines, E., \& Pellegrini, A. (2003). The social context of school playground games: Sex and ethnic differences, and changes over time after entry to junior school. British Journal of Developmental Psychology, 21, 481-505.

Chagas, D. V., \& Batista, L. A. (2017). Comparisons of health outcomes among children with different levels of motor competence. Human Movement, 18, 56-61.

Cliff, D. P., Okely, A. D., Smith, L., \& Mckeen, K. (2009). Relationships between fundamental movement skills and objectively measured physical activity in pre-school children. Pediatric Exercise Science, 21, 436-449.

Cohen, J. (1988). Statistical power analysis for the behaviour science (2nd ed.). New York, NY: Lawrence Erlbaum Associated.

Cools, W., De Martelaer, K., Samaey, C., \& Andries, C. (2009). Movement skill assessment of typically developing preschool children: A review of seven movement skill assessment tools. Journal of Sports Science and Medicine, 8, 154-168.

Davies, M. (2003). Movement and dance in early childhood (2nd ed.). London, United Kingdom: Paul Chapman Publishing.

Flatters, I., Hill, L. J. B., Williams, J. H. G., Barber, S. E., \& Mon-Williams, M. (2014). Manual control age and sex differences in 4 to 11 year old children. PLOS ONE, 9(2), e88692.

Foulkes, J. D., Knowles, Z., Fairclough, S. J., Stratton, G., O’Dwyer, M., Ridgers, N. D, \& Foweather, L. (2015). Fundamental movement skills of preschool children in Northwest England. Perceptual and Motor Skills, 121, 260-283.

Gallahue, D. L., Ozmun, J. C., \& Goodway, J. D. (2011). Understanding motor development: Infants, children, adolescents, adults (7th ed.). New York, NY: McGraw-Hil.

Hanlon, H. W., Thatcher, R. W., \& Cline, M. J. (1999). Gender differences in the development of EEG coherence in normal children. Developmental Neuropsychology, 16, 479-506.

Hardy, L. L., King, L., Farrell, L., Macniven, R., \& Howlett, S. (2009). Fundamental movement skills among Australian preschool children. Journal of Science and Medicine in Sport, 13, 503-508.

Haywood, K. M., \& Getchell, N. (2014). Life span motor development (6th ed.). Champaign, IL: Human Kinetics.

Henderson, S. E., Sugden, D. A., \& Barnett, A. L. (2007). Movement Assessment Battery for Children-2 (MABC-2): 
Examiner's manual. London, United Kingdom: Pearson Assessment.

Kokštejn, J., Musálek, M., \& Tufano, J. J. (2017). Are sex differences in fundamental motor skills uniform throughout the entire preschool period? PLOS ONE, 12(4), e0176556.

Kourtessis, T., Tsougou, E., Maheridou, M., Tsigilis, N., Psalti, M., \& Kioumourtzoglou, E. (2008). Developmental coordination disorder in early childhood: A preliminary epidemiological study in Greek schools. International Journal of Medicine, 1, 95-99.

LeGear, M., Greyling, L., Sloan, E., Bell, R. I., Williams, B. L., Naylor, P.-J., \& Temple, V. A. (2012). A window of opportunity? Motor skills and perceptions of competence of children in Kindergarten. International Journal of Behavioral Nutrition and Physical Activity, 9, 29.

Lingam, R., Hunt, L., Golding, J., Jongmans, M., \& Emond, A. (2009). Prevalence of developmental coordination disorder using the DSM-IV at 7 years of age: A UK population-based study. Pediatrics, 123, e693-e700.

Livesey, D., Coleman, R., \& Piek, J. (2007). Performance on the Movement Assessment Battery for Children by Australian 3- to 5-year-old children. Child: Care, Health and Development, 33, 713-719.

Malina, R. M. (2004). Motor development during infancy and early childhood: overview and suggested directions for research. International Journal of Sport and Health Science, 2, 50-66.

Nelson, K. R., Thomas, J. R, \& Nelson J. K. (1991). Longitudinal change in throwing performance: gender differences. Research Quarterly for Exercise and Sport, 62, 105-108.

Okely, A. D., Booth, M. L., \& Patterson, J. W. (2001). Relationship of physical activity to fundamental movement skills among adolescents. Medicine \& Science in Sports \& Exercise, 33, 1899-1904.

Psotta, R. (2014). MABC-2: Test motoriky pro děti (1. české vydání) [The Movement Assessment Battery for Children-2 test (1st Czech ed.)]. Prague, Czech Republic: Hogrefe-Testcentrum.

Research Pedagogical Institute in Prague. (2006). Framework educational programme for preschool education 2004. Prague, Czech Republic: ÚIV, TAURIS.

Schoemaker, M. M., Lingam, R., Jongmans, M. J., van Heuvelen, M. J., \& Emond, A. (2013). Is severity of motor coordination difficulties related to co-morbidity in children at risk for developmental coordination disorder? Research in Developmental Disabilities, 34, 3084-3091.

Shala, M. (2009) Assessing gross motor skills of Kosovar preschool children. Early Childhood Development and Care, 179, 969-976.

Sigmundsson, H., \& Rostoft, M.-S. (2003). Motor development: Exploring the motor competence of 4-year-old Norwegian children. Scandinavian Journal of Educational Research, 47, 451-459.
Singh, D. K. A., Rahman, N. N. A. A., Rajikan, R., Zainudin, A., Nordin, N. A. M., Karim, Z. A., \& Yee, Y. H. (2015). Balance and motor skills among preschool children aged 3 to 4 years old. Malaysian Journal of Medicine and Health Sciences, 11, 63-68.

Spessato, B., Gabbard, C., Valentini, N., \& Rudisill, M. (2013). Gender differences in Brazilian children's fundamental movement skill performance. Early Child Development and Care, 183, 916-923.

Stodden, D. F., Goodway, J. D., Langendorfer, S. J., Roberton, M. A., Rudisill, M. E., Garcia, C., \& Garcia, L. E. (2008). Developmental perspective on the role of motor skill competence in physical activity: An emergent relationship. Quest, 60, 290-306.

Sugden, D., \& Wade, M. (2013). Typical and atypical motor development. London, United Kingdom: Mac Keith Press.

Temple, V. A., Crane, J. R., Brown, A., Williams, B. L., \& Bell, R. I. (2016). Recreational activities and motor skills of children in kindergarten. Physical Education and Sport Pedagogy, 21, 268-280.

Thomas, J. R. (2000). 1999 C. H. McCloy research lecture: Children's control, learning, and performance of motor skills. Research Quarterly for Exercise and Sport, 71, 1-9.

Thomas, J. R., \& French, K. E. (1985). Gender differences across age in motor performance: A meta-analysis. Psychological Bulletin, 98, 260-282.

Valtr, L., Psotta, R., \& Abdollahipour, R. (2016). Gender differences in performance of the Movement Assessment Battery for Children-test in adolescents. Acta Gymnica, 46, 155-161.

van Beurden, E., Zask, A., Barnett, L. M., \& Dietrich U. C. (2002). Fundamental movement skills - how do primary school children perform? The 'Move it Groove it' program in rural Australia. Journal of Science and Medicine in Sport, $5,244-252$.

Van Waelvelde, H., Peersman, W., Lenoir, M., Smits Engelsman, B. C. M., \& Henderson, S. E. (2008). The Movement Assessment Battery for Children: Similarities and differences between 4- and 5-year-old children from Flanders and the United States. Pediatric Physical Therapy, 20, 30-38.

Vandaele, B., Cools, W., de Decker, S., \& de Martelaer, K. (2011). Mastery of fundamental movement skills among 6-year-old Flemish pre-school children. European Physical Education Review, 17, 3-17.

Venetsanou, F., \& Kambas, A. (2011). The effects of age and gender on balance skills in preschool children. Physical Education and Sport, 9, 81-90.

Vlachos, F., Papadimitriou, A., \& Bonoti, F. (2014). An investigation of age and gender differences in preschool children's specific motor skills. European Psychomotricity Journal, 6, 16-18. 